\title{
The Diagnosis and Treatment of Sjögren's Syndrome
}

\author{
Ana-Luisa Stefanski, Christian Tomiak, Uwe Pleyer, Thomas Dietrich, \\ Gerd Rüdiger Burmester, Thomas Dörner
}

\section{SUMMARY}

Background: Sjögren's syndrome is one of the more common inflammatory rheumatological diseases, with a prevalence of at least $0.4 \%$ in Germany.

Methods: This review is based on pertinent articles retrieved by a selective search in PubMed. Special attention is drawn to updated classification criteria and current treatment recommendations.

Results: Sjögren's syndrome has a wide variety of presentations, ranging from the local involvement of exocrine glands with keratoconjunctivitis sicca and xerostomia (the leading signs of the disease) to the systemic, extraglandular involvement of multiple organs. Fatigue also markedly worsens the patients' quality of life. Serologic testing reveals antinuclear auto-antibodies (anti-Ro/ SSA and anti-La/SSB) as well as rheumatoid factors. The histological hallmark of the disease is focal lymphocytic infiltration in otherwise normal-appearing glandular acini. The disease also markedly elevates the risk of non-Hodgkin lymphoma of the B-cell series, which arises in about $5 \%$ of patients. Primary Sjögren's syndrome (pSS) differs from the secondary form (sSS), which appears in the setting of another autoimmune disease, particularly systemic lupus erythematosus (15-36\%), rheumatoid arthritis (20-32\%), and limited or progressive systemic sclerosis (11-24\%). Disease-modifying therapy is reserved for patients with systemic involvement; there is limited evidence for its efficacy. Because of the complexity of this disease, some of its clinical manifestations may require interdisciplinary treatment.

Conclusion: The main considerations in the interdisciplinary care of patients with Sjögren's disease are measures to improve quality of life, pharmacological and non-pharmacological treatments to keep disease activity in check, and management of the risk of lymphoma. Future therapeutic approaches must take the heterogeneity of the disease into account.

\section{$\checkmark$ Cite this as:}

Stefanski AL, Tomiak C, Pleyer U, Dietrich T, Burmester GR, Dörner T:

The diagnosis and treatment of Sjögren's syndrome. Dtsch Arztebl Int 2017; 114: 354-61. D0l: 10.3238/arztebl.2017.0354

\footnotetext{
Charité Center for Internal Medicine, Medical Department-Division of Rheumatology and Clinica Immunology, Berlin, Germany: Prof. Dr. med. Burmester, Dr. med. Stefanski, Prof. Dr. med. Dörner University Clinic of Rheumatology, Immunology and Allergology, Inselspital Bern, Bern, Switzerland: Dr. med. Stefanski

BfA Wendelstein Rehabilitation Clinic, Rheumatology Center, AHB Clinic, Bad Aibling, Germany: Dr. med. Tomiak

Department of Ophthalmology, Charité Campus Virchow, Berlin, Germany: Prof. Dr. med. Pleyer

Oral Surgery, The School of Dentistry, University of Birmingham, United Kingdom: Prof. Dr. med. Dr. med. dent. Dietrich
}

jögren's syndrome is a chronic inflammatory - autoimmune disease of unknown origin, attacking in particular the tear and salivary glands. Sicca symptoms are the hallmarks of the disease which may also present with various organ manifestations. Due to the wide variety of signs and symptoms, patients with Sjögren's syndrome may see a diverse range of healthcare practitioners, including family physicians, ophthalmologists, ENT specialists, and dentists, at the first consultation. Thus, it is crucial for physicians of various specialties to be informed about current aspects of clinical manifestations of the disease, the revised classification criteria, and current treatment options.

Primary Sjögren's syndrome (pSS) is distinguished from secondary Sjögren's syndrome (sSS) which occurs as a part of other autoimmune diseases. sSS coexists especially with systemic lupus erythematosus (15-36\%), rheumatoid arthritis $(20-32 \%)$ as well as limited and progressive systemic sclerosis (11-24\%), less frequently with multiple sclerosis and autoimmune hepatitis and thyreoiditis (1). Here, the term "secondary" does not describe a chronological sequence of disease manifestation: The underlying condition may initially present with sicca symptoms and only later reveal itself over the course of the disease. Establishing the diagnosis is often challenging in patients with overlapping disease entities. Given the distinct courses of disease (including prognosis), it is important to differentiate between the primary and secondary form of Sjögren's syndrome.

\section{Epidemiology}

The heterogeneity of the available prevalence and incidence data for Sjögren's syndrome is explained by differences in study design and classification criteria. The global prevalence calculated for the rarer pSS is 61 per 100000 inhabitants, with the highest prevalence encountered in Europe (2). Women develop Sjögren's syndrome significantly more frequently than men; the sex difference ranges between 9:1 to 19:1. Mean age at time of first diagnosis of pSS is 56 years, with another peak occurring between 20 and 40 years. However, first symptoms may occur years before diagnosis. As yet, there is a lack of reliable epidemiological data for Germany. The overall prevalence of Sjögren's syndrome, including the more 
Dry eye/keratoconjunctivitis sicca Normal tear production (Schirmer's test unremarkable)

- Environmental factors (air conditioning, smoking, computer work)

- Meibomian gland dysfunction, rosacea

- Contact lenses

- Corneal hypoesthesia after LASIK surgery, along with diabetes

- Incomplete lid closure

\section{Reduced tear production (abnormal Schirmer's test)}

- Drug-induced: Anticholinergics, antihistamines,

tricyclic antidepressants, diuretics

- Age-related/menopause

- Status post head/neck radiation

- Chronic viral infections (HCV, HIV)

- Sarcoidosis, lymphoma

- Sjögren's syndrome (primary and secondary)

- IgG4-related disease

Xerostomia

- Drug-induced: anticholinergics, antihistamines, tricyclic antidepressants, diuretics, antihypertensive drugs, among others

- Anxiety disorder, endogenous depression, fibromyalgia, bulimia/anorexia

- Status post head/neck radiation

- Systemic disease (sarcoidosis, amyloidosis, HCV, HIV)

Parotid swelling

Mainly unilateral Mainly bilateral

- Acute: Bacterial infection, actinomycosis, mechanical obstruction by salivary duct stones

- Chronic: Chronic sialadenitis, neoplasia (pleomorphic adenoma of the parotid gland)

- Acute: Viral infection (mumps, EBV, CMV)

- Chronic: Chronic infections (HCV, HIV), diabetes mellitus, alcoholism, anorexia amyloidosis, IgG4-related disease, hyperlipoproteinemia

CMV, cytomegalovirus; EBV, Epstein-Barr virus; $\mathrm{HCV}$, hepatitis-C virus; LASIK surgery, laser in-situ keratomileusis

common secondary form of the disease, is assumed to be at least $0.4 \%(3)$.

\section{Clinical manifestation}

According to the largest cohort published so far, sicca symptoms are the most common manifestation of Sjögren's syndrome, with up to $98 \%$ of cases (4). Patients with keratoconjunctivitis sicca (KCS) complain about foreign-body sensation, burning or soreness of the eyes and increased sensitivity to light. Marked xerostomia as a sign of stomatitis sicca presents clinically as difficulties when talking for extended periods of time and while chewing or insalivating dry food. Compared with the general population, the prevalence of dental caries and early tooth loss is about twice as high in patients with Sjögren's syndrome and their oral healthrelated quality of life is significantly reduced. Recurrent oral infections with Candida albicans occur 10 times more frequently than in the general population (5). On the other hand, sicca symptoms are commonly reported with advancing age and polypharmacy: Approximately $5 \%$ to $35 \%$ of the general population suffer from dry eyes (6), and approximately $20 \%$ of dental patients experience dry mouth (7). Thus, a thorough medical history, including medications, and physical examination, followed by special function tests, is crucial for the interpretation of these complaints. Table 1 lists the differential diagnoses for glandular complaints. In addition, attention should be paid to other sicca symptoms, such as dry cough in tracheobronchitis sicca or sicca symptoms in the nasopharynx or genital tract, manifesting as an increased susceptibility to infection or as dyspareunia.
Up to $34 \%$ of patients with Sjögren's syndrome report episodic or chronic, typically bilateral swelling of the parotid glands (9). Here, it is essential to exclude malignant non-Hodgkin lymphoma (NHL) of B cell lineage which occurs in about $5 \%$ of patients with pSS (10) who are at a significantly increased risk of developing NHL compared with the general population (risk ratio [RR]: 13.7). Key predictors for the development of NHL include low complement levels (RR: 8.3), cryoglobulinemia (RR: 6.8), lymphadenopathy (RR: 3.7), histological finding of ectopic germinal centerlike structures, permanent swelling of parotid gland, and skin vasculitis $(10,11)$. These patients belong to a high-risk group and require monitoring at closer intervals and, if necessary, further diagnostic investigations, such as chest radiography and abdominal ultrasound; however, valid recommendations for lymphoma screening are not available.

The most common extraglandular manifestations are arthralgia and a usually non-erosive polyarthritis which occur in approximately $50 \%$ of patients (9). Pulmonary involvement beyond the sicca complex typically manifests as interstitial lung disease or follicular bronchiolitis, normally after many years of disease activity $(9-12 \%)(9,12)$. About $10 \%$ of patients have cutaneous lesions, the majority in form of a vasculitis with involvement of small and medium vessels of the lower limbs. In addition, other less common skin manifestations may occur, such as annular erythema, urticarial vasculitis, or hypergammaglobulinemic purpura (9). Renal involvement, which is found in approximately $5 \%$ of patients, is usually associated with 


\section{New classification criteria (modified according to [20])}

- Current European-American consensus criteria for the classification of primary Sjögren's syndrome

- Unstimulated salivary flow rate ${ }^{* 1}$ abnormal $\leq 0.1 \mathrm{~mL} /$ minute

- Abnormal Schirmer's test ( $<5 \mathrm{~mm}$ in 5 minutes)

- Abnormal findings with lissamine green or fluorescein staining

( $\geq 5$ in Ocular Staining Score or $\geq 4$ in Van Bijsterveld Score)

- Autoantibody detection: anti-Ro/SSA

- Histology ${ }^{\star 2}$ _focal lymphocytic sialadenitis, Focus score $\geq 1$ focus $/ 4 \mathrm{~mm}^{2}$, 1 focus $=50$ lymphocytes $/ 4 \mathrm{~mm}^{2}$

\section{- Diagnosis is considered established if score $\geq 4$ points, after application of inclusion and exclusion criteria}

- Inclusion criteria:

Dryness of eyes and/or mouth for at least 3 months, not explained otherwise (e.g. medications, infection)

- Exclusion criteria:

Status post head/neck radiation, HIVIAids, sarcoidosis, active infection with hepatitis $\mathrm{C}$ virus (PCR replication rate), amyloidosis, graft-versus-host disease, IgG4-related disease

- The lack of any other potentially associated disease is the key requirement for classification as a pSS.

*1 The patient is asked to sit still, not to speak or to chew for 5 to 15 minutes; the saliva produced during this time is transferred to a test tube and weighed.

*2 Biopsy: Removal of 3 to 5 labial minor salivary glands from the lower lip under local anesthesia; fixation of biopsy material in formalin and HE staining; caution: local paresthesia after biopsy

$\mathrm{HE}$, hematoxylin and eosin stain; PCR, polymerase chain reaction

tubulointerstitial changes which frequently go along with distal renal tubular acidosis (RTA type 1) with hypokalemic muscular hypotonia; glomerulonephritis is rare in patients with pSS $(9,13)$.

Also of clinical relevance is the involvement of the peripheral nervous system, especially later in the course of the disease, typically manifesting as sensory neuropathy $(10-25 \%)(9,14)$. Rarer and more challenging to identify are CNS manifestations; for example, the differential diagnosis of multifocal CNS lesions on MRI includes multiple sclerosis lesions which are difficult to distinguish from pSS lesions (15). In this context, the coexistence of pSS with neuromyelitis optica spectrum disorders (NMOSD), which are characterized by autoantibodies to aquaporin-4, is of importance (4). If patients test positive for this antibody, this is of great differential therapeutic significance.

By contrast, nonspecific complaints such as fatigue and diffuse pain are more difficult to evaluate. However, fatigue is the symptom experienced as most distressing by the patient, determining physician visit frequency, quality of life as well as fitness for work $(16, \mathrm{e} 1)$. Other conditions in the differential diagnosis of fatigue, such as hypothyroidism, anemia and sleep disorders, should be excluded and difficulties in coping with the disease should also be taken into account.
Anti-Ro/SSA- and anti-La/SSB-positive women desiring to have children require special counseling. Placental transmission of these antibodies can cause inflammation with subsequent sclerosis of the atrioventricular (AV) node which carries the risk of the fetus developing a congenital heart block. In $80 \%$ of cases, complete irreversible heart block occurs and in $20 \%$ fetal mortality is significantly increased (17). Weekly ultrasonographic monitoring of the cardiac rhythm of the fetus between 16 and 31 weeks' gestation is essential for both prognostic evaluation and management.

\section{Prognosis}

Overall, the prognosis of Sjögren's syndrome is favorable. The life expectancy of pSS patients is comparable with that of the general population (18). However, the patients' quality of life is reduced by the diverse manifestations of the disease. Cardiovascular disease, infections, solid tumors, and lymphoma are the main causes of death. In patients with sSS, life expectancy is determined by the primary disease.

\section{Pathogenesis}

As with most autoimmune diseases, the etiology of Sjögren's syndrome is not yet fully understood (e2-e5, 19). Current concepts of its pathogenesis are summarized in the eFigure. 


\section{Classification criteria and diagnostic evaluation}

Since the 1970s, various classification criteria have been established and evaluated. Recently, the existing US criteria from 2012 were for the first time integrated in the current classification by the major societies, ACR (American College of Rheumatology) and EULAR (European League Against Rheumatism). In patients having experienced sicca symptoms for at least 3 months, these are based on further function tests (e.g. the Schirmer's test) or serological (Anti-Ro/SSA) and histological examinations (labial salivary gland biopsy). Among these investigations, anti-Ro/SSA antibodies and an abnormal labial salivary gland biopsy have the highest specificity; consequently, they are the criteria with the highest values. A minimum score of 4 allows for classification as Sjögren's syndrome (Box). The Figure shows a diagnostic algorithm for Sjögren's syndrome, based on the revised classification criteria and the various disease manifestations.

\section{Objective tests for sicca symptoms}

Schirmer's test and Saxon's test are easy to perform, but their results do not correlate well with patient complaints and should be evaluated in the overall context. Here, cooperation with the ophthalmology department is crucial: Topical application of vital stains (lissamine green or fluorescein) is used to visualize and grade corneal and conjunctival lesions associated with keratoconjunctivitis sicca. Direct measurement of salivation is the diagnostic gold standard, but it is time consuming in daily clinical practice. Parotid sialography and salivary gland scintigraphy lack sufficient specificity. As a noninvasive method, ultrasonography of the major salivary glands is an integral part of daily clinical practice. However, the method is not yet sufficiently validated to be include in the classification criteria (21).

\section{Laboratory testing}

Immunofluorescence testing for antinuclear antibodies (ANA) is highly relevant for the diagnosis of connective tissue disorders. Up to $83 \%$ of patients with pSS test positive for ANA (22). However, low-titer $(<1: 160)$ and unspecific ANA patterns are also found in $5 \%$ to $20 \%$ of the general healthy population (23). In patients with positive ANA titers, a fine speckled fluorscence pattern is strongly indicative of anti-Ro/SSA and/or anti-La/SSB antibodies, which is revealed in approximately $40 \%$ to $75 \%$ and $23 \%$ to $52 \%$ of pSS patients, respectively (24). With the recent increase in diagnostic value assigned to anti-Ro/SSA antibodies in the current classification system, it can be expected that significantly more newly classified Sjögren's syndrome patients will have elevated antibody levels compared with historical cohorts. Positive antibody titers correlate with early onset of disease, more intense tissue infiltration, and higher prevalence of extraglandular manifestations. However, patients with other connective tissue disorders may also test positive for anti-
FIGURE

$$
\begin{aligned}
& \text { Screening questions } \\
& \text { - Dry eyes }>3 \text { months } \\
& \text { - Dry mouth }>3 \text { months } \\
& \text { Possible basic evaluation } \\
& \text { - Unstimulated salivary flow rate } \\
& \text { - Schirmer's test } \\
& \text { - lissamine green or fluorescein test } \\
& \text { - ANA immunofluorescence } \\
& \text { ANA titer, Ro/SSA titer } \\
& \text { - labial salivary gland biopsy } \\
& \text { Focus score } \geq 1 \text { focus/4 mm }{ }^{2} \\
& \text { Extended diagnostic evaluation } \\
& \text { (examples depending on symptoms/ESSDAI) } \\
& \text { - Arthrosonography, joint tap } \\
& \text { - PFT, HRCT, 6-minute walking test } \\
& \text { - Head MRI, ENMG, spinal tap } \\
& \text { - Caution: non-Hodgkin lymphoma } \\
& \text { - During pregnancy: } \\
& \text { Caution: congenital heart block }
\end{aligned}
$$

Diagnostic algorithm of Sjögren's syndrome

ANA, antinuclear antibodies; ENMG, electroneuromyography;

ESSDAI, EULAR - Sjögren's syndrome disease activity index; HRCT, high-resolution computed tomography;

PFT, pulmonary function test

Ro/SSA antibodies. Here, the clinical context is vital, especially to differentiate between overlapping disease entities. Interestingly, serological autoimmune phenomena have been detected up to 20 years before the appearance of the first signs and symptoms of the disease (25). Other serological abnormalities include the presence of rheumatoid factors $(60-75 \%)$ as well as polyclonal hypergammaglobulinemia as a sign of increased B cell activity.

The development of biomarkers, providing prognostic information and a means to monitor disease progression, has now reached the establishment phase. An increase in beta2-microglobulin and free light chains of immunoglobulins is associated with an increased risk of lymphoma (26). Siglec-1 has recently emerged as a new biomarker. This indirect interferon marker correlates with a high level of disease activity as well as extraglandular manifestations (27).

\section{Histopathology}

The histopathological finding of focal periductal localized lymphocytic infiltrates in exocrine glandular tissue along with otherwise intact acinar units is pathognomonic for Sjögren's syndrome. These infiltrations mostly consists of $\mathrm{CD}^{+} \mathrm{T}$ cells, with some additional $\mathrm{CD}^{+} \mathrm{T}$ cells and $\mathrm{CD} 19^{+} \mathrm{B}$ cells, plasma cells and dendritic cells. Deep expertise in line with international recommendations on the interpretation of histopathological findings is required to differentiate Sjögren's syndrome from other disease entities (28). A minimum number of 50 monocytic 
TABLE 2

Treatment recommendations for sicca symptoms and fatigue in patients with primary Sjögren's syndrome (modified according to [30])

\begin{tabular}{|c|c|}
\hline Indication & Treatment (grade of recommendation) \\
\hline $\begin{array}{l}\text { Keratoconjunctivitis } \\
\text { sicca }\end{array}$ & $\begin{array}{l}\text { - Patient education/avoid anticholinergics/ tear substitutes } \\
\text { (A) } \\
\text { - Secretagogues: Pilocarpine, cevimeline* (A) } \\
\rightarrow \text { Caution: sweating, flush, headache, nausea } \\
\text { - Cyclosporine A eye drops } 0.1 \% \text { (B) } \\
\rightarrow \text { Caution: burning of eyes in case of moderate to severe } \\
\quad \text { corneal damage } \\
\text { - Short-term topical corticosteroids (C) } \\
\rightarrow \text { Caution: glaucoma, cataract } \\
\text { - Punctal plugs (C), scleral lenses (C) }\end{array}$ \\
\hline Stomatitis sicca & $\begin{array}{l}\text { - Patient education/avoid drugs that promote xerostomia (A) } \\
\text { - Topical fluorides for caries prevention (A) } \\
\text { - Secretagogues: Pilocarpine, cevimeline* (A) } \\
\rightarrow \text { Caution: sweating, flush, headache, nausea } \\
\text { - Saliva substitutes, sugar-free chewing gum, } \\
\text { electrostimulation of salivary glands (C) }\end{array}$ \\
\hline Rhinitis sicca & $\begin{array}{l}\text { - Nasal oil } \\
\rightarrow \text { Caution: no decongestant nasal drops }\end{array}$ \\
\hline $\begin{array}{l}\text { Tracheobronchitis } \\
\text { sicca }\end{array}$ & $\begin{array}{l}\text { - Pilocarpine, bromhexine, inhalation with saline, avoiding } \\
\text { dehydrating substances (e.g. chamomile) }\end{array}$ \\
\hline Dyspareunia & - Estrogen-containing vaginal suppository \\
\hline Fatigue & $\begin{array}{l}\text { - Aerobic endurance training (B) } \\
\text { - Hydroxychloroquine (C) } \\
\quad \rightarrow \text { Caution: annual ophthalmological follow-ups }\end{array}$ \\
\hline
\end{tabular}

Grades of Recommendation according to Centre for Evidence-based Medicine in Oxford:

(A) Evidence obtained from meta-analyses or at least one randomized controlled trial

(B) Evidence from at least one well-designed experimental study

(C) Evidence from at least one well-designed descriptive study or case-control studies

(D) Evidence from expert opinion

* In Germany, cevimeline is only available via international pharmacies.

cells $/ 4 \mathrm{~mm}^{2}$ was defined as a focus score (FS) of 1 . A focus score $\geq 1$ correlates with the phenotypical characteristics of Sjögren's syndrome.

\section{Management}

Despite continued advances in our understanding of the mechanisms involved in the pathogenesis of the disease, a targeted treatment of Sjögren's syndrome is not available at present. Treatment is decided on an individual basis according to disease activity and the presence and extent of extraglandular manifestations. In patients with $\mathrm{sSS}$, the indication for treatment is based on the underlying disease. In general, treatment should be provided by an interdisciplinary team, including family physicians, rheumatologists, ophthalmologists and ETN specialists, as well as dentists. Subject to the organ(s) involved and the presenting symptoms, consultation of other specialists (gynecologists, pulmonologist, neurologists, etc.) may be required. Disease-modifying therapy is reserved for patients with extraglandular involvement. To measure systemic disease activity, the EULAR Sjögren's Syndrome Disease Activity Index (ESSDAI) was developed and validated (29, e7).

\section{Management of sicca symptoms}

In most patients, the main aim of therapy is to improve quality of life by treating the sicca and fatigue symptoms. At the same time, this is a very challenging task for physicians as evidence-based treatment options are scarce and most therapeutic approaches are only symptomatic (Table 2). Patient education plays an important role, focusing on compliance with everyday behavioral rules (30) - targeting environmental factors (e.g., air humidification), prevention (e.g., fluoride for caries prevention, quit smoking), and avoidance of factors that increase fatigue (e.g., sleep hygiene) as well as physical fitness (aerobic endurance training to fight fatigue).

Various tear substitutes are available to treat keratoconjunctivitis sicca. The composition of the tear substitutes varies in accordance with the complex physiology of the three-layered preocular tear film (lipid layer, aqueous layer, and mucin layer). Since immunemediated mechanisms play a central role in the pathogenesis of dry eye, anti-inflammatory treatment with cyclosporine A eye drops has gained significant importance. Their efficacy has been proven in randomized controlled trials (RCTs) and, based on data from these studies, $0.1 \%$ cyclosporine A cationic emulsion received marketing authorization from the European Medicines Agency (31). Additional measures significantly increasing the quality of life of these patients include the use of punctal plugs and the fitting of extra-large contact lenses ("scleral lenses") with water storage function (32). Thus, cooperation with ophthalmologists is essential.

Xerostomia is treated jointly by dentists and otolaryngologists. The oral mucosal surface is comparatively large and different structures in the oral cavity need to be moistened (tongue, teeth, gum, oral mucosa). In addition, saliva composition varies with function and time of day. Optimal therapeutic compensation of the complex functions of saliva cannot be achieved. Two systematic reviews on topical/nonpharmacological treatments arrive at the conclusion that, while symptoms can be alleviated, the flow of saliva cannot be increased $(33,34)$. Dental care for patients with xerostomia is particularly challenging, as the lack of saliva reduces the tolerability of removable dental restorations. By contrast, in patients with Sjögren's syndrome good outcomes are achieved with dental implant treatment (35).

\section{Disease-modifying therapy}

The decision to intensify treatment is dependent on disease activity and the organ system involved. However, the few RCTs evaluating the use of conventional disease-modifying antirheumatic drugs (DMARDs) or biologic agents in patients with Sjögren's syndrome did not provide conclusive evidence supporting their efficacy $(30,36)$. Treatment decisions are frequently based on experiences with related rheumatic disease entities, such as systemic lupus erythematosus. Analog to other connective tissue disorders, hydroxychloroquine, an 
agent with a favorable side-effect profile, is the drug of choice for various mild to moderate systemic manifestations, such as arthralgia, arthritis, cutaneous lesions, and fatigue. The example of hydroxychloroquine highlights the challenges with regard to study design and the selection of patients who may benefit from treatment. A randomized controlled trial on pSS found no difference between hydroxychloroquine und placebo regarding sicca symptoms, pain and fatigue after 24 weeks (37). However, this study had significant limitations: The disease activity in these patients was low, the follow-up period short, and the primary endpoint not validated. To increase the validity of future RCTs investigating this heterogeneous disease, it is essential to recruit representative patient groups and select robust primary endpoints.

With regard to fatigue, a pilot study demonstrated moderate efficacy for rituximab (38). Unfortunately, this was not confirmed by a large RCT conducted some years later (39).

Treatment recommendations with regard to immunosuppression vary according to organ involvement (Table 3). In patients with severe organ manifestations, the use of high-dose methylprednisolone and cyclophosphamide is of proven effectiveness. For severe vasculitis, especially with concomitant cryoglobulinemia, rituximab or plasmapheresis are the recommended treatment options. In patients with NHL, treatment is chosen based on subentity and stage according to current guidelines on the treatment of hemato-oncological disorders.

The recommended treatment for pregnant women with Sjögren's syndrome and a high risk for congenital heart block is hydroxychloroquine to minimize risk; however this recommendation is solely based on evidence from retrospective studies (40).

New treatment approaches, targeting pathophysiological mechanisms, are currently being evaluated in RCTs with validated instruments (ESSDAI): modulation of B-cell hyperactivity (e.g., belimumab), antagonizing T-cell co-stimulation (e.g., abatacept), effector cytokines (e.g., interleukin-6-receptor/tocilizumab; interferon $\alpha /$ anifrolumab), as well as prevention of the formation of ectopic germinal center-like structures (e.g., lymphotoxin- $\beta \mathrm{R}$ blockade). These studies face the challenge to demonstrate efficacy for the three symptom complexes-sicca, fatigue, and extraglandular manifestations.

\section{Conflict of interest statement}

Prof. Dörner received consultancy fees from UCB, Novartis and Roche as well as financial support for the conduct of clinical studies from UCB and Novartis. Prof. Pleyer received consultancy and lecture fees from Santen, Théa, and Allergan.

Prof. Burmester received financial support for the conduct of clinical studies from Novartis, UCB and Roche.

Dr. Stefanski, Dr. Tomiak and Prof. Dietrich declare that no conflict of interest exists.

Manuskript received on 13 December 2016; revised version accepted on 14 March 2017

\section{TABLE 3}

Treatment recommendations for systemic manifestations of primary Sjögren's syndrome (modified according to [30])

\begin{tabular}{|c|c|}
\hline Indication & Treatment (Grade of Recommendation) \\
\hline Parotid swelling & $\begin{array}{l}\text { - NSAIDs and short-term oral corticosteroids } \\
\text { (<20 mg/d for max. } 1 \text { month) (D) } \\
\rightarrow \text { consideration of contraindications } \\
\text { - Antibiotic treatment, if required (D) }\end{array}$ \\
\hline Arthritis & $\begin{array}{l}\text { - Hydroxychloroquine (C) } \\
\rightarrow \text { Caution: annual ophthalmological follow-ups } \\
\text { - NSAIDs, short-term oral/intraarticular corticosteroids (C); } \\
\rightarrow \text { consideration of contraindications } \\
\text { - Second-line DMARDs as with rheumatoid arthritis (C), } \\
\text { (especially methotrexate [D] } \rightarrow \text { Caution: renal failure) }\end{array}$ \\
\hline $\begin{array}{l}\text { Interstitial } \\
\text { pneumopathy }\end{array}$ & $\begin{array}{l}\text { - Corticosteroids, oral or intravenous (C) } \\
\rightarrow \text { consideration of contraindications } \\
\text { - Cyclophosphamide for active alveolitis (C) } \\
\rightarrow \text { Caution: hemorrhagic cystitis, pancytopenia, fertility } \\
\text { - Pirfenidone, Nintedanib (C) } \\
\rightarrow \text { Caution: hepatic impairment }\end{array}$ \\
\hline $\begin{array}{l}\text { Tubulointerstitial } \\
\text { nephritis }\end{array}$ & $\begin{array}{l}\text { - Potassium and bicarbonate replacement (D) } \\
\rightarrow 3 \times 1-2 \text { g/day }\end{array}$ \\
\hline Peripheral neuropathy & $\begin{array}{l}\text { - Antidepressants, gabapentin (D) } \\
\rightarrow \text { Caution: sicca } \\
\text { - Corticosteroids, oral or intravenous, IVIg (D) } \\
\rightarrow \text { consideration of contraindications }\end{array}$ \\
\hline $\begin{array}{l}\text { Cryoglobulinemic } \\
\text { vasculitis with organ } \\
\text { involvement }\end{array}$ & $\begin{array}{l}\text { - Methylprednisolone, plasmapheresis }(\mathrm{C}) \\
\rightarrow \text { consideration of contraindications } \\
\text { - Rituximab }(\mathrm{C}) \\
\rightarrow \text { Caution: infusion reaction, formation of immune } \\
\text { complexes, infections }\end{array}$ \\
\hline B-cell lymphoma & - Treatment protocols according to subentity and stage \\
\hline
\end{tabular}

Close monitoring of patients treated with DMARDs or immunosuppressants according to the recommendations of the German Society of Rheumatology (dgrh.de/therapieueberwachen.html) Grades of Recommendation according to Centre for Evidence-based Medicine in Oxford:

(A) Evidence obtained from meta-analyses or at least one randomized controlled trial;

(B) Evidence from at least one well-designed experimental study;

(C) Evidence from at least one well-designed descriptive study or case-control studies;

(D) Evidence from expert opinion;

DMARDs, disease-modifying antirheumatic drugs;

IVIg, intravenous immunoglobulins;

NSAID, nonsteroidal anti-inflammatory drugs 
KEY MESSAGES

- If sicca symptoms persist for more than 3 months, Sjögren's syndrome should be suspected once adverse drug reactions and other potential causes have been excluded.

- ANA-Titers $>1$ : 160 with fine granular ANA pattern are indicative of the possibility of anti-Ro/SSA and/or antiLa/SSB antibodies.

- Anti-Ro/SSA antibodies and abnormal labial salivary gland biopsy results have the highest diagnostic specificity for Sjögren's syndrome.

- Quality of life, organ manifestations and lymphoma risk represent important aspects of the interdisciplinary treatment and follow-up.

- Extraglandular manifestations are treated with immunosuppressants/DMARDs according to the organ involved; the efficacy of biologic agents remains unproven for this indication.

\section{REFERENCES}

1. Tomiak C, Dorner T: Sjogren's syndrome. Current aspects from a rheumatological point of view. Z Rheumatol 2006; 65: 505-17.

2. Qin B, Wang J, Yang Z, et al.: Epidemiology of primary Sjögren's syndrome: a systematic review and meta-analysis. Ann Rheum Dis 2015; 74: 1983-9.

3. Westhoff G, Zink A: Epidemiology of primary Sjogren's syndrome. Z Rheumatol 2010; 69: 41-9.

4. Brito-Zeron P, Theander E, Baldini C, et al.: Early diagnosis of primary Sjögren's syndrome: EULAR-SS task force clinical recommendations. Expert Rev Clin Immunol 2016; 12: 137-56.

5. Fox PC, Bowman SJ, Segal B, et al.: Oral involvement in primary Sjögren syndrome. J Am Dent Assoc 2008; 139: 1592-601.

6. Bron AJ, Tomlinson A, Foulks GN, et al.: Rethinking dry eye disease: a perspective on clinical implications. Ocul Surf 2014; 12: 1-31.

7. Villa A, Abati S: Risk factors and symptoms associated with xerostomia: a cross-sectional study. Aust Dent J 2011; 56: 290-5.

8. Cornec D, Saraux A, Jousse-Joulin S, et al.: The differential diagnosis of dry eyes, dry mouth, and parotidomegaly: a comprehensive review. Clin Rev Allergy Immunol 2015; 49: 278-87.

9. Ramos-Casals M, Brito-Zeron P, Solans R, et al.: Systemic involvement in primary Sjögren's syndrome evaluated by the EULAR-SS disease activity index: analysis of 921 Spanish patients (GEAS-SS Registry). Rheumatology (Oxford) 2014; 53: 321-31.

10. Nishishinya MB, Pereda CA, Munoz-Fernandez S, et al.: Identification of lymphoma predictors in patients with primary Sjögren's syndrome: a systematic literature review and meta-analysis. Rheumatol Int 2015; 35: 17-26.

11. Theander $E$, Vasaitis $L$, Baecklund $E$, et al.: Lymphoid organisation in labial salivary gland biopsies is a possible predictor for the development of malignant lymphoma in primary Sjögren's syndrome. Ann Rheum Dis 2011; 70: 1363-8.

12. Flament T, Bigot A, Chaigne B, Henique H, Diot E, Marchand-Adam S: Pulmonary manifestations of Sjögren's syndrome. Eur Respir Rev 2016; 25: 110-23.

13. Evans R, Zdebik A, Ciurtin C, Walsh SB: Renal involvement in primary Sjögren's syndrome. Rheumatology (Oxford) 2015; 549: 1541-8.

14. Pavlakis PP, Alexopoulos H, Kosmidis ML, et al.: Peripheral neuropathies in Sjögren's syndrome: a critical update on clinical features and pathogenetic mechanisms. J Autoimmun 2012; 39: 27-33.

15. Harms L, Hiepe F: Neurological manifestations in connective tissue disease. Z Rheumatol 2012; 71: 564-71.

16. Westhoff G, Dörner T, Zink A: Fatigue and depression predict physician visits and work disability in women with primary Sjogren's syndrome: results from a cohort study. Rheumatology (Oxford) 2012; 51: 262-9.

17. Brito-Zeron P, Izmirly PM, Ramos-Casals M, Buyon JP, Khamashta MA:

The clinical spectrum of autoimmune congenital heart block. Nat Rev Rheumatol 2015; 11: 301-12.

18. Singh AG, Singh S, Matteson EL: Rate, risk factors and causes of mortality in patients with Sjögren's syndrome: a systematic review and meta-analysis of cohort studies. Rheumatology (Oxford) 2016; 55: 450-60.

19. Moutsopoulos HM: Sjögren's Syndrome: autoimmune epithelitis Clinical Immunology and Immunopathology 1994; 72: 162-5.

20. Shiboski CH, Shiboski SC, Seror R, et al.: 2016 American College of Rheumatology/European League Against Rheumatism classification criteria for primary Sjögren's syndrome: a consensus and datadriven methodology involving three international patient cohorts. Arthritis Rheumatol 2017; 69: 35-45.

21. Cornec D, Devauchelle-Pensec V, Saraux A, Jousse-Joulin S: Clinical usefulness of salivary gland ultrasonography in Sjögren's syndrome: where are we now? Rev Med Interne 2016; 37: 186-94.

22. Nardi N, Brito-Zeron P, Ramos-Casals M, et al.: Circulating autoantibodies against nuclear and non-nuclear antigens in primary Sjögren's syndrome: prevalence and clinical significance in 335 patients. Clin Rheumatol 2006; 25: 341-6.

23. Pisetsky DS: Antinuclear antibodies in healthy people: the tip of autoimmunity's iceberg? Arthritis Res Ther 2011; 13: 109.

24. Patel R, Shahane A: The epidemiology of Sjögren's syndrome. Clin Epidemiol 2014; 6: 247-55.

25. Theander E, Jonsson R, Sjostrom B, Brokstad K, Olsson P, Henriksson G: Prediction of Sjögren's syndrome years before diagnosis and identification of patients with early onset and severe disease course by autoantibody profiling. Arthritis Rheumatol 2015; 67: 2427-36

26. Gottenberg JE, Seror R, Miceli-Richard C, et al.: Serum levels of beta2-microglobulin and free light chains of immunoglobulins are associated with systemic disease activity in primary Sjögren's syndrome. Data at enrollment in the prospective ASSESS cohort. PLoS One 2013; 8: e59868.

27. Rose T, Szelinski F, Lisney A, et al.: SIGLEC1 is a biomarker of disease activity and indicates extraglandular manifestation in primary Sjögren's syndrome. RMD Open 2016; 2: e000292.

28. Daniels TE, Cox D, Shiboski CH, et al.: Associations between salivary gland histopathologic diagnoses and phenotypic features of Sjögren's syndrome among 1,726 registry participants. Arthritis Rheum 2011; 63: 2021-30.

29. Seror R, Bowman SJ, Brito-Zeron P, et al.: EULAR Sjögren's syndrome disease activity index (ESSDAl): a user guide. RMD Open 2015; 1 : e000022.

30. Saraux A, Pers J0, Devauchelle-Pensec V: Treatment of primary Sjögren syndrome. Nat Rev Rheumatol 2016; 12: 456-71.

31. Leonardi A, Van Setten G, Amrane M, et al.: Efficacy and safety of $0.1 \%$ cyclosporine A cationic emulsion in the treatment of severe dry eye disease: a multicenter randomized trial. Eur $\mathrm{J}$ Ophthalmol 2016; 26: 287-96.

32. Romero-Rangel T, Stavrou P, Cotter J, Rosenthal P, Baltatzis S, Foster CS: Gas-permeable scleral contact lens therapy in ocular surface disease. Am J Ophthalmol 2000; 130: 25-32.

33. Furness S, Worthington HV, Bryan G, Birchenough S, McMillan R: Interventions for the management of dry mouth: topical therapies. Cochrane Database Syst Rev 2011; (12): CD008934. 
34. Furness S, Bryan G, McMillan R, Worthington HV: Interventions for the management of dry mouth: non-pharmacological interventions. Cochrane Database Syst Rev 2013; (8): CD009603.

35. Albrecht K, Callhoff J, Westhoff G, Dietrich T, Dorner T, Zink A: The prevalence of dental implants and related factors in patients with Sjogren syndrome: results from a cohort study. J Rheumatol 2016; 43: $1380-5$

36. Carsons SE, Vivino FB, Parke A, et al.: Treatment guidelines for rheumatologic manifestations of Sjogren's: use of biologics, management of fatigue and inflammatory musculoskeletal pain. Arthritis Care Res (Hoboken) 2016.

37. Gottenberg JE, Ravaud P, Puechal X, et al.: Effects of hydroxychloroquine on symptomatic improvement in primary Sjögren syndrome: the JOQUER randomized clinical trial. JAMA 2014; 312: 249-58.

38. Dass S, Bowman SJ, Vital EM, et al.: Reduction of fatigue in Sjögren's syndrome with rituximab: results of a randomised, double-blind, placebo controlled pilot study. Ann Rheum Dis 2008; 67: $1541-4$

39. Bowman S, Everett C, Bombardieri M, et al.: Preliminary results of a double-blind randomised trial of rituximab anti-B-cell therapy in patients with primary Sjogrens syndrome. Arthritis Rheumato 2015; 67: 3955-7.

40. Izmirly PM, Kim MY, Llanos C, et al.: Evaluation of the risk of antiSSA/Ro-SSB/La antibody-associated cardiac manifestations of neonatal lupus in fetuses of mothers with systemic lupus erythematosus exposed to hydroxychloroquine. Ann Rheum Dis 2010; 6910: 1827-30.

\section{Corresponding author}

Dr. med. Ana-Luisa Stefanski

Charite Universitatsmedizin Berlin

Rheumatologie und klinische Immunologie

Charitéplatz

10117 Berlin, Germany

Ana-Luisa.Stefanski@charite.de

Supplementary material

For eReferences please refer to:

www.aerzteblatt-international.de/ref2017

eFigure:

www.aerzteblatt-international.de/17m0354

\section{CLINICAL SNAPSHOT}

\section{Decompensated Right Heart Failure Caused by Large Tumor Masses}
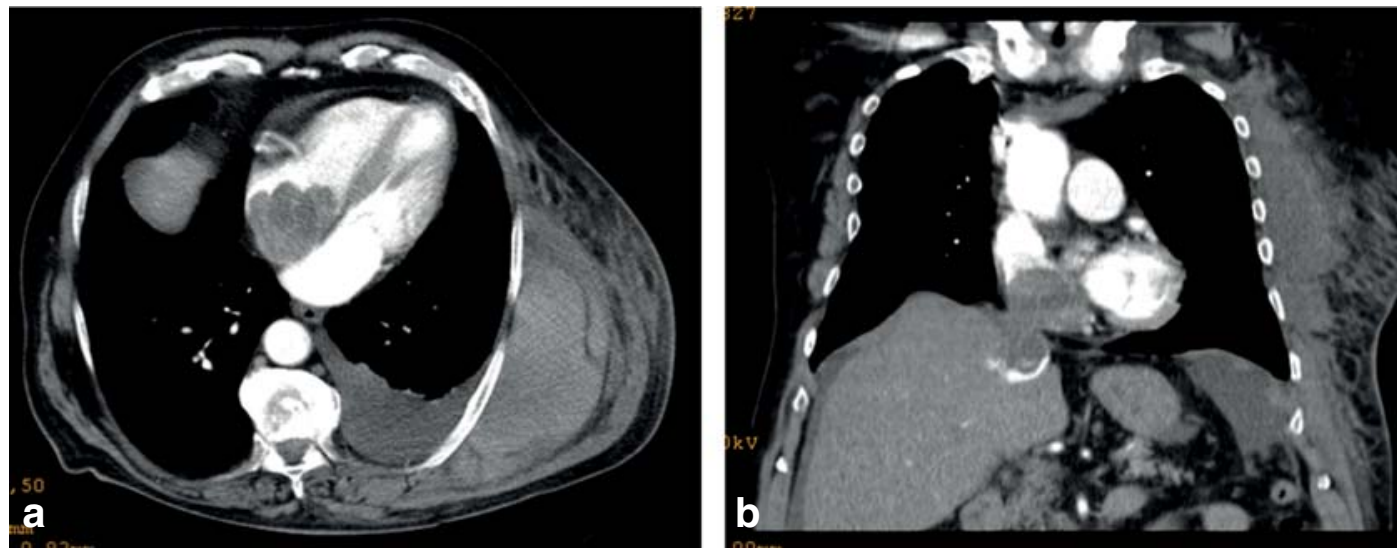

Cardiac and upper abdominal CT reveals a polyp-like tumor $(58 \times 55 \mathrm{~mm})$ in the right atrium. The tumor is a attached to the floor of the right atrium and b) extends through the ostium of the inferior vena cava into the hepatic venous outlets.

A 70-year-old man presented to the hospital with diffuse abdominal symptoms and ankle edema. Diagnostic studies revealed a hepatic parenchymal abnormality and marked ascites, and a liver biopsy was performed via laparoscopy. Histological examination revealed extensive subacute acinocentral parenchymal necrosis, which was interpreted as being due to right heart failure. After medical treatment for right heart failure, the transaminases returned to the normal range (GOT $24.7 \mathrm{U} / \mathrm{L}$ [10.0-50.0], GPT $22.2 \mathrm{U} / \mathrm{L}$ [10.0-50.0]), while the cholestatic parameters remained mildly elevated (AP $140.0 \mathrm{U} / \mathrm{l}$ [40-129], yGT $168 \mathrm{U} / \mathrm{L}[<66]$ ). Recurrent pulmonary embolism was suspected, and a chest CT was obtained. This surprisingly revealed a mass measuring ca. $6 \mathrm{~cm}$ in the right atrium, extending caudally into the inferior vena cava and hepatic venous outlets. There was also a lesion measuring $3 \mathrm{~cm}$ in segment 8 of the right lobe of the liver. The right atrial tumor was removed and histological examination revealed fragments of a well-differentiated primary hepatocellular carcinoma. The patient declined oncologic treatment against medical advice and died of this disease.

Sebastian Barth, Martina B. Hautmann, Abteilung Kardiologie, Herz- und Gefäßklinik Bad Neustadt a.d. Saale, sebastian.barth@kardiologie-bad-neustadt.de Alexander Calderoni, Klinik für allgemeine Innere Medizin, Gastroenterologie und Diabetologie, Augusta Kliniken gGmbH, Bochum

\section{Conflict of interest statement}

The authors declare that no conflict of interest exists.

Cite this as: Barth S, Hautmann MB, Calderoni A: Decompensated right heart failure caused by large tumor masses.. Dtsch Arztebl Int 2017; 114: D0I: 10.3238/arztebl.2017.0361 


\section{Supplementary material to:}

\section{The Diagnosis and Treatment of Sjögren's Syndrome}

by Ana-Luisa Stefanski, Christian Tomiak, Uwe Pleyer, Thomas Dietrich, Gerd Rüdiger Burmester, and Thomas Dörner

Dtsch Arztebl Int 2017; 114: 354-61. D0l: 10.3238/arztebl.2017.0354

\section{eREFERENCES}

e1. Segal BM, Pogatchnik B, Holker E, et al.: Primary Sjogren's syndrome: cognitive symptoms, mood, and cognitive performance. Acta Neurol Scand 2012; 125: 272-8.

e2. Cruz-Tapias P, Rojas-Villarraga A, Maier-Moore S, Anaya JM: HLA and Sjögren's syndrome susceptibility. A meta-analysis of worldwide studies. Autoimmun Rev 2012; 11: 281-7.

e3. Reksten TR, Lessard CJ, Sivils KL: Genetics in Sjögren syndrome. Rheum Dis Clin North Am 2016; 42: 435-47.

e4. Hall JC, Baer AN, Shah AA, et al.: Molecular subsetting of interferon pathways in Sjögren's syndrome. Arthritis Rheumatol 2015; 67: 2437-46.

e5. Mavragani CP, Crow MK: Activation of the type I interferon pathway in primary Sjögren's syndrome. J Autoimmun 2010; 35: 225-31.

e6. Hansen A, Dörner T: Sjögren syndrom. Internist (Berl) 2010; 51: 1267-79.

e7. Seror R, Theander E, Brun JG, et al.: Validation of EULAR primary Sjögren's syndrome disease activity (ESSDAl) and patient indexes (ESSPRI). Ann Rheum Dis 2015; 74: 859-66. 


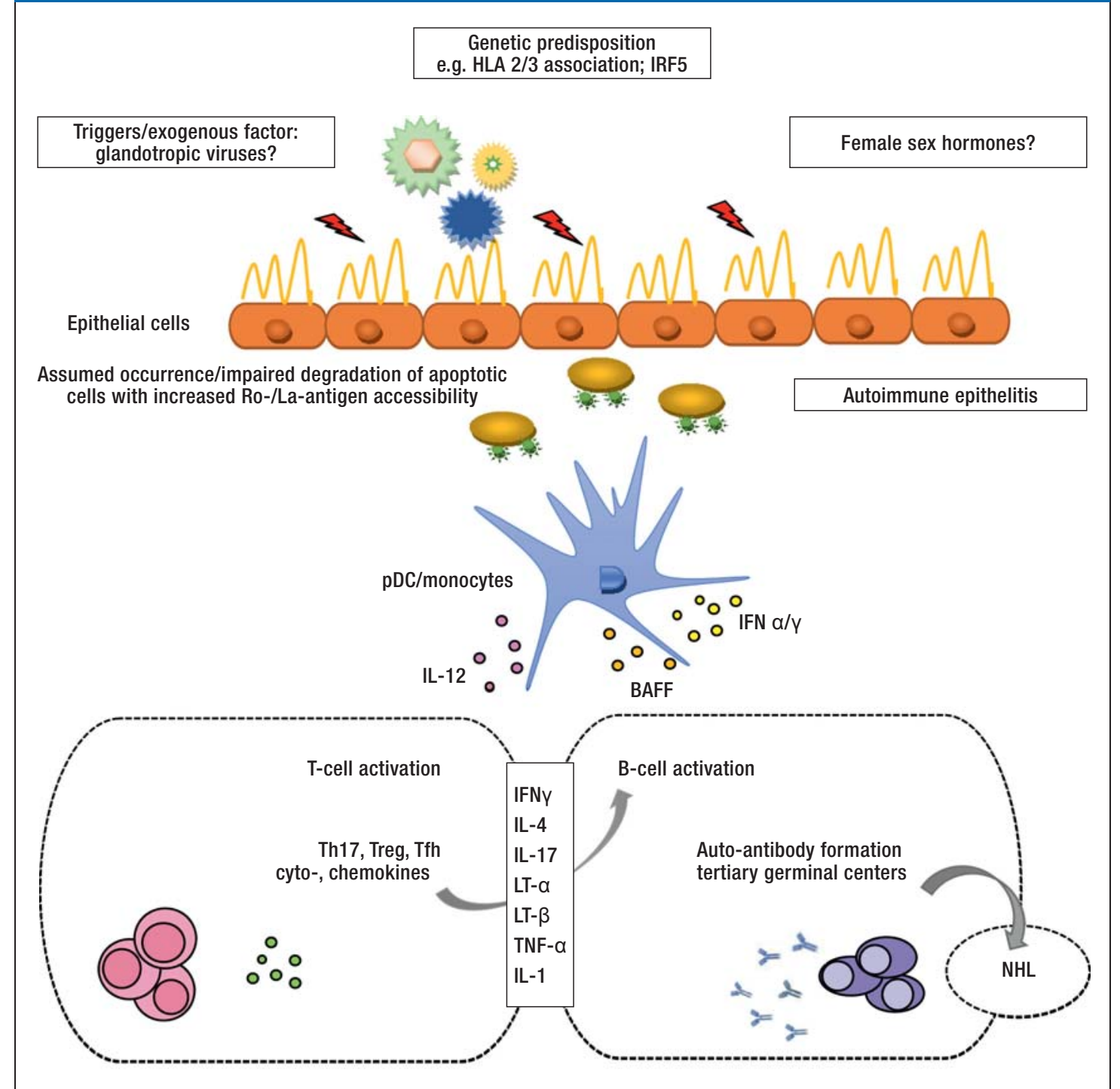

Diagram of the pathogenesis of Sjögren's syndrome (modified according to [e6])

Genetic predisposition (e2, e3), exogenous triggering factors (e.g. glandotropic viruses) and hormonal changes are thought to initiate and maintain the immunopathogenesis of the disease. Glandular epithelial cells supposedly play a central pathophysiological role in the development of auto-immune epithelitis, especially with regard to antigen presentation of Ro/SSA- and La/SSB-protein complexes which are found on the surface of apoptotic cells (19). Both the innate (e.g. pDC/monocytes) and the adaptive immune system (T-/B-cells) are involved in the initiation of the disease and perpetuation of the immune response (e5, e6). Via the activation of various $\mathrm{CD} 4^{+} \mathrm{T}$-helper cell subsets, $\mathrm{B}$ cells play an important role in auto-antibody production, from the formation of ectopic germinal center-like structures to the malignant transformation to NHL (11).

BAFF, B cell-activating factor of the tumor necrosis factor family; HLA, human leukocyte antigen; IFN $\alpha / \gamma$, interferon $\alpha / \gamma$; IL-1, -4, -12, -17, interleukin 1, 4, 12, 17; IRF5, interferon regulatory factor 5 ; LT- $\alpha$, lymphotoxin $\alpha$; LT- $\beta$, lymphotoxin $\beta$; NHL, Non-Hodgkin lymphoma; pDC, plasmacytoid dendritic cells; Tfh, follicular T cells; Th17, T helper cells 17;

TNF- $\alpha$, tumor necrosis factor $\alpha$; Treg, regulatory T cells 